\title{
Towards Achieving Benefits of IT Utilization in Collaboration Networks
}

\author{
Iris Karvonen \\ VTT Industrial Systems, P.O. Box 1000, 02044 VTT, Finland \\ Iris.Karvonendvtt.fi
}

\begin{abstract}
Information technology, with the recent developments towards Future Internet, creates expectations for enterprises and collaboration networks about ease of use and high business benefits. However, the benefits are not an automatic outcome of an IT system take-up. In addition to technical aspects, organizational implementation is needed, with user participation and enterprise collaboration in the process. This paper discusses the challenges and barriers of IT implementation in collaborative networks, with the aim to identify success factors for achieving the benefits. The study is based on previous research and uses the experience of collaboration business cases of COIN project (EU FP7 ICT 216256).
\end{abstract}

Keywords: Collaboration networks, IT utilization, interoperability, SMEs.

\section{Introduction}

Most SMEs today operate in some kind of collaboration networks, offering efficiency, flexibility and access to knowledge, capabilities and customers which they could not reach alone. There are different forms of cooperation, from the long term collaboration networks to short term consortiums or virtual organizations (VO) [20]. The long term networks may have different levels of preparedness [31], from more sustainable and prepared "VO breeding environments" [3] to less tight business ecosystems [24]. Today collaboration is spreading increasingly from traditional manufacturing to other areas like co-creation, product development and service provision, to support the whole product lifecycle.

Information and communication technology systems and services are not only support but also enablers for collaboration. Efficient information exchange with supporting infrastructure is not any more a competitive edge but a necessity for SMEs. Especially globally distributed operations, requiring enterprise collaboration and interoperability, benefit from Information technology (IT) services. IT, developing towards Future Internet systems, enables also SMEs to participate in global activities as part of supply chains, collaborative networks or business ecosystems. Advanced platforms, tools and services to support Enterprise collaboration and interoperability have been developed for example in past EUfunded research projects ECOLEAD and ATHENA and recently in COIN (Collaboration and Interoperability in networked Enterprises) [5]. This paper is based on the work performed in COIN. The development in COIN has been performed in 
continuous interaction with 6 end user organizations, representing collaboration networks (CN), supply chains (DC) or business ecosystems (BE) in different industrial fields, including automotive, aerospace, aeronautics, pulp\& paper engineering, healthcare and ICT-industry. These organizations which have been involved in the development from requirements to testing are called COIN end users in this paper.

Recently, supporting business innovation has been seen to become an important objective for future enterprise systems [10]. The visions in Future Internet Enterprise Systems and cloud computing foresee services to be available "on-fly", with low cost and with more flexible configuration, scalability and openness [9]. The services will be available through generic service platforms and the need for local technical software set-ups will decrease. Thus, the technical barriers for IT utilization are envisaged to decrease. The availability of low cost services should also remove some economic constraints, at least for "mass-services".

However, showing the full benefit of the ICT requires that not only technology but organizational aspects, how to use the technology in the organization and between organizations, are taken into account in the take-up process. It is foreseen that "the power in the development of future enterprise systems will progressively move from IT specialists to business experts" [10]. As the technology is expected to evolve into easier and more usable systems and services, the significance of the organizational take-up process will increase.

\section{IT Implementation Challenges}

Information technology providers claim remarkable gains when using their services. However, for companies, especially SMEs, it may be challenging to achieve the expected benefits by IT take-up. It is often difficult to understand how to use the technology, what are the objectives behind and how the processes should be changed. The high resources, knowledge and capabilities required for the take up seem to restrain the adoption of IT in SMEs: "Often small and medium-sized companies will not have the knowledge or resources available to carry out the configuration, adaptation, or integration work by themselves" [8]. "The actual implementation of use of ICT in business processes, especially those involving customers and suppliers, remains limited." [9] Especially SMEs suffer of unfinished IT projects, unrealized savings, delays and exceeding the take-up costs. Experiences gained in earlier implementation projects affect the future user's attitudes for a new implementation project [19] and may hinder the will to start new implementations.

Lack of awareness of the possibilities and benefits that ICT could offer is also considered as one barrier for ICT adoption by SMEs [9]. The technology and vendors with approaches from onsite to cloud-based solutions make many SMEs confused and willing to wait until the market settles down [29]. On the other hand, when always following others' the enterprises cannot be in the lead, gaining the potential competitive advantages [22].

Additionally, there is the problem of sharing the benefits: Some manufacturing SMEs see that the benefits of IT utilization do not come for them but accumulate at the end of the manufacturing process [32]. A similar observation can be seen on user 
level [7]: "the value may be obvious at the level of an enterprise but not as evident at the individual level". This decreases the motivation for change which is needed at the end user level, to make success at the company or network level.

The barriers are familiar also for enterprises interested in innovative solutions. The six end users of COIN project [5] identified the following main obstacles: not knowing about the potential and the benefits clearly enough, the benefits going to someone else, high costs, additional work, risks, resistance to change, too complex implementation, not believing in security, not knowing the sustainability of the solution etc. To overcome these obstacles they suggest strategic approach, success stories and demonstration of benefits as well as service provider support. Also customers requiring the take-up of novel solutions would contribute to the implementation of new solutions and processes.

The benefits created by technology are of course dependent on its usability. However, the same IT solution does not necessarily give the same advantages in different companies. The same system may not fit all the cases and the main question often is, how the technology is used in the organization. The decisions are made and realized in the organizational implementation process. That is why, in addition to software usability, the implementation process is important [15]. It does not only affect the costs or schedule of the start-up of the system, but also how the system is used in the long run and how the processes of the organization are modified, the roles defined etc. [18].

In the take up process the organizations must be able to determine which goals they wish to reach with the system [28], often the processes need to be re-defined and the individual end users need to be committed to the system use. The implementation project has proved to be challenging. Some previous studies have shown failure in about half to two-thirds of information system projects [28]. Even business losses have been reported [34, 17]. For complex IT systems, like ERP (Enterprise Resource Planning), the failure percentage has been assessed to be even higher: in early takeups in 1990's about $90 \%$ of the implementation projects were reported to fail at the first attempt [12] or "three quarters of ERP system installations were judged unsuccessful by the companies paying the bills" [13]. Still in 2000's "Many ERP implementation projects are geared towards failure, out-of-budget deployments, implementations unable to deliver the expected functionality or, in the best case, delays." [2]. Because of the challenges, the IT implementation success has become a relevant research issue, not only in the ERP field, but also in e-Business, enterprise portals, web applications etc [for example 2,4,23,26]. The need for organizational implementation has been identified.

IT implementation is defined as "the entire process from needs analysis and choice of technological solution, to the realization of the full benefits from the technology" [25]. Other terms used for the task are system roll-out and system transition [16]. The starting point is as soon as the decision about the IT implementation has been made and the focus is on the implementation in the organization, not in software development.

As seen above, the take-up of complex IT systems is challenging already in one organization. In collaboration networks, in an inter-enterprise environment the challenges of IT take-up are even higher: 
- $\quad$ The partners are independent enterprises, they have greater autonomy [25] and the decision-making is distributed. It may be difficult to reach a common decision about the IT take-up and understanding about the new processes. Take-up of systems or services supporting collaboration is not fully successful if all partners are not interested and capable of using them.

- The systems or services are not always as beneficial for each enterprise - for some they may create benefit, while for some others the system may mean only additional work.

- Inter-enterprise environment has additional complexity because of more units, functions, and locations.

- There are more differences in concepts, cultures, processes, practices, skills and management styles between network partners.

- Openness is not always accepted between organizations. Thus more careful specification of access rights is needed than inside one organization.

- Companies may collaborate within several networks. They are not willing to take up and use many parallel systems.

Thus, the organizational implementation process needs to be extended to an interorganizational process. Inter-organizational ICT implementation may be defined as the process and actions required to adopt the ICT tools \& services into operational use in the network, including the necessary process changes and end user participation.

\section{Development Approach}

As described in the previous sector, the availability of an IT solution does not guarantee the business benefits when taking it into use. Thus, from the research point of view, it is not enough to develop new technology. It is important also to consider how the technology could be best utilized and through which processes and actions each organization and network can achieve the benefits. One way to approach this is to identify the best practices or critical success factors for take-up of EC \& EI solutions. They could serve as guiding principles or a check list of actions, processes or conditions that need to be fulfilled to achieve the expected results in an interenterprise environment.

This paper focuses on the identification of critical success factors for the context of Enterprise Collaboration (EC) and Enterprise Interoperability (EI) services. As a starting point research about IT adoption, organizational implementation and conditions for enterprise system success has been reviewed. Critical success factors of IT implementation identified in previous research were reviewed and consolidated to a list of 17 items. This is described in chapter 4.1. The research base was enriched and adapted using the experience of COIN end users. The preliminary views of the end users were collected by interviews and survey templates and discussed in workshops. The list was added with specific factors relating to the context of interorganizational collaboration, coming from the observations of the end users. The resulting list of 23 factors is presented in chapter 4.2.

Finally, to validate the critical success factors in the context of EC \& EI take up, the list was developed into a questionnaire to the end users. The questionnaire asked the end users to assess for each factor: 
- the importance of the factor in the context of IT supporting collaboration and interoperability (with scale not important.. highly important),

- the current level of practice: Is the factor currently considered and put into practice in the network/ ecosystem of the end user organization when taking up IT solutions (always-often-sometimes-seldom-never)?

The questionnaire was distributed to COIN end users. Because of the project internal use only, the group of respondents was, of course, quite small but on the other hand, the replying end users especially represented enterprises for which collaboration is important. The results are described in chapter 4.3.

In addition to the identification of the importance of the presented factors the results can be used to indicate which factors (processes, practices) have the largest gaps within this group of end users. The gaps have been measured for each factor as the ratio of average importance rating and the average current usage:

Gap = average importance rate / average current level of practice,

where

the average importance rate is the average of different users' assessments given with scale from 1..5 (not important .. very important) and the average current level of practice is the average of the users' assessments given also by $1 . .5$ (with neverseldom-sometimes-often-always).

Thus the gap "indicator" should identify the factors which are important but seldom taken into account in the organizations and which would thus need more attention. The results can be used to emphasize both the important and the usually ignored practices and for developing guidance for end users when taking up EC \& EI services.

\section{Critical Success Factors (CSFs) for EC and EI Take Up}

\subsection{Previous Research of CSFs in IT Implementation}

To support successful implementation, IT research has identified best practices as critical success factors, guiding the activities of organizations in the implementation process. Critical success factors (CSF) are defined as "the limited number of areas in which results if they are satisfactory, will ensure successful competitive performance of the organization" [27] or "key areas of performance that are essential for the accomplishment of a mission or project, i.e. the fields in which satisfactory results ensure the attainment of goals". [2] Thus CSFs describe the activities and conditions for success, not only being in time and budget but also achieving the expected benefits. IT research has reviewed the CSFs for ERP implementation, e-commerce or enterprise portals, mainly for single organizations [27, 33]. The focus has been in organizational change [21], measuring the relevance of CSFs with benefits based on case experiences [14,23,30], studying the interrelations [1], timing of CSFs in different phases of the implementation [11], in different types of organizations [2] etc. The factors given in different sources are largely similar and overlapping, even if their order of importance may be different for different application areas [27]. 


\subsection{Adaptation for Inter-organizational Environment}

Critical success factors of EC \& EI implementation represent the factors that are needed to ensure the success of EC \& EI solution take-up. To define the CSFs for EC $\&$ EI context the factors presented in previous research were collected and consolidated together into a list of 17 success factors, classified into 6 groups.

In a collaboration environment the success is not dependent alone of one company but may require the participation of several organizations. Thus some of the factors were modified because of the inter-organizational aspect. Based on the preliminary discussions with COIN end users also 6 factors relevant for collaboration environment were added (marked with * below). This resulted to the following list of 23 potential factors:

1. Management and vision:

1.1 Top management support, participation, commitment and involvement

1.2 The vision of the collaboration is clear and shared*

1.3 The take-up has clear goals and objectives.

1.4 Common decision of the take-up*

2. Solution selection

2.1 Selection with minimal customization

2.2 Sustainability of the service*

2.3 Service offering future innovation*

2.4 The solution business model $\&$ prizing clear and acceptable*

3. Organization of take-up

3.1 Take-up team has sufficient competencies and skills.

3.2 Excellent Take-up Project management

3.3 Consideration of multi-site issues - Local champions.

4. System and process adaptation

4.1 Adaptation of existing practices, identify inter-organizational processes affected

4.2 Readiness of organizational culture for cooperation, change and participation

4.3 Take into account balance of power and homogeneity

5. Practices towards end users

5.1 User involvement into the take-up process

5.2 Collaboration maturity*

5.3 Adequate training program

5.4 Strong communication inwards and outwards

5.5 Creation of incentives for collaboration, participation and information sharing

6. Take-up phases

6.1 Time box philosophy

6.2 Phased take-up approach

6.3 Analyze the interfaces with legacy/other systems

6.4 Managing post-implementation process.

The content of the factors and their sources have been described more in [6].

\subsection{Results of End User Assessment}

This list, with supporting descriptions, was used as the basis for the identification of their relevance in the EC \& EI context, using a questionnaire to the end users [6], as described above. The responding group was quite small; with six end user 
organizations of which seven replies were received. Thus the results should also be assessed with this restriction; they are not telling the final importance of the factors but give anyway some preliminary information from users knowing well the EC \& EI domain challenges. The results of the questionnaire showed that all the success factors which were considered critical in previous IT research, were assessed important also in this group of collaborating enterprises: they all had the average rate above 3,5 (scale 1..5) and most of them had an average rate above 4. All the additional factors relating to collaboration had the average rate above 4 . Within this group of enterprises the following factors were seen most important:

- Having or creating a clear and shared vision of collaboration: The partners in the CN/BE/SC need to understand the benefits and goals of collaboration and have a common vision of the future.

- Using time box philosophy in the take up: take-up plan offering benefits at different stages. Performance measures of benefits should be followed.

- The services should offer future innovation, possibility for scaling up and further development.

- The take-up team must have sufficient competencies and skills, including knowledge from past deployments and technology readiness. Multifunctional/organizational team is recommended.

- The take-up should be supported by excellent project management at the $\mathrm{CN} / \mathrm{BE} / \mathrm{SC}$ level, depending on the take-up size and scope. Purposeful planning with formalized project plan, project monitoring and controlling, use of steering committee, risk management, competent project manager are recommended.

- Collaboration maturity of the participating organizations, including trust, should be at sufficient level in the network. Previous experience of collaboration is needed.

Thus, according to this group, these practices and conditions are the most important to take into account when taking up EC \& EI solutions in a collaborative environment. However, their importance is not highly different from the other factors. Thus the list should not be "cut" but all the factors should be taken into account. A more detailed presentation of the observed rates of importance within COIN end user group is presented in [6].

Even if all the factors were generally identified important, the companies are not usually following these practices. The rate of practice or factor usage was below 3,2 for all the factors and for most factors less than 3 (meaning that the practice is sometimes applied). Thereby it seems that these practices are not commonly taken into practice even if the enterprises recognize them important and belong to the group of enterprises interested in innovation. Thus there is a need for this type of guiding list to support enterprises in their take up processes.

When comparing the importance and the usage with the "gap indicator" (as described in chapter 3) the largest gaps were identified for the following factors:

- The end users would like to be able to select the solution/ service business model, for example as a service or as a utility. The prizing is clear and acceptable. Currently they are not able to do this. 
- The organizational change management, adaptation of existing practices, designing to-be processes, identifying inter-organizational processes affected and aligning the functionality with the business processes are considered important but not sufficiently considered in practical take-up cases of collaborating organizations.

- According to the end users the take-up teams do not usually have sufficient competencies and skills.

- The multi-site / multi-organization issues are not considered sufficiently. Local champions, translating the take-up vision into reality from the local viewpoint and solving problems, is recommended to support the take-up in a distributed organization / different organizations.

- The balance of power and homogeneity, group cohesion and social capital are not sufficiently handled in organizations and networks within the take up. Psychological safety and recognition decrease the resistance and increase motivation of users.

Three of these gaps come from low level of usage (seldom) and only one of the factors assessed in the six most important belong to this group. The full list of the values of the gap indicators is presented in [6].

\section{Conclusions}

This paper discusses the challenges of IT implementation in inter-enterprise environment, in the context of Enterprise Collaboration and Enterprise Interoperability services. The main focus is in the identification of critical success factors for EC \& EI service take up. Based on previous research and COIN end user experience critical success factors were identified, organized and finally validated by industrial end users participating in COIN project.

The analysis within this group of six networked end user organizations showed that all the criteria defined for the single organizations were relevant also for interorganizational take up, but additionally six factors coming from the EC \& EI context were needed. These consider, for example, collaboration maturity, common vision of the collaboration, common decision of the take up and offer for future innovation and scalability. Furthermore, the application of the different practices or principles behind the critical success factors was studied within the end user group. The result was that the common level of application or usage was low for most factors. This is partly due to underestimating the resources needed to create common understanding about the future concept which the IT is aimed to support. A measure of "gap indicator" was defined as the ratio of average importance rating and the average current usage of a factor. The gap indicator is able to reveal factors or practices that are not taken into practice sufficiently even if they are recognized important.

The analysis was in this phase restricted in quite a small, COIN internal group. In future it would be interesting to extend it to larger user groups to see if there are differences in the importance or in the current practices between application fields. The reasons behind the gaps should be analyzed more in the future. Within the development towards Future Internet Enterprise Systems, which are expected to offer more ease of technical take up, it is important to increase the awareness of both end 
users and the supporting software providers about the organizational requirements of IT implementation. Future Internet research should also include a topic about IT innovations, from the end user viewpoint, taking into account user-oriented and userinvolved development.

Acknowledgement. This work has been partly funded by the European Commission through ICT Project COIN: Collaboration and Interoperability for networked enterprises.

\section{References}

1. Akkermans, H., van Helden, K.: Vicious and virtuous cycles in ERP implementation: a case study of interrelations between critical success factors. European Journal of Information Systems 11, 35-46 (2002)

2. Araujo, I.: Critical Success Factors for ERP Deployments in International Federation for Information Processing. In: Tjoa, A.M., Xu, L., Chaudhry, S. (eds.) Research and Practical Issues of Enterprise Information Systems, vol. 205, pp. 319-324. Springer, Boston (2006)

3. Camarinha-Matos, L.M., Afsarmanesh, H., Ollus, M. (eds.): Methods and Tools for Collaborative Networked Organizations. Springer, New York (2008)

4. Carneiro, L., Alves, A., Carneiro, D., Wolf, C., Macey, J., San Martin, F., Ballester, F.: Methodology for the implementation of e-Business solutions in SMEs. In: Stanford-Smith, B., Chiozza, E. (eds.) E-work and E-commerce. Novel Solutions and Practices for a Global Networked Economy, vol. 1, pp. 106-112. IOS Press, Amsterdam (2001)

5. COIN project (EU-FP7-216256), http: / /www . coin-ip.eu/

6. COIN: COIN (EU-FP7-216256) Deliverable D64.1b EC \&EI inter-organizational implementation methods (to be published, 2011)

7. EC: Value Proposition for Enterprise Interoperability ref version 3, 3. EC (December 2007), http://cordis . europa.eu/ist/ict-ent-net/isg.htm

8. EC: eBusiness Guide for SMEs. eBusiness Software and Services in the European Market. European Communities 2008 (2008), http://ec.europa.eu/enterprise/ebsn/ebusiness-solutionsguide/docs/eBusiness_Guide_for_SMEs.pdf

9. EC: FInES Position Paper. Final version 1.9.2009. Future Internet Enterprise Systems (FInES) Cluster. European Communities (2009)

10. EC: FInES Position Paper on Orientations for FP8. A European Innovation Partnership for European Enterprises. Final Version 18.3.2011. Future Internet Enterprise Systems (FInES) Cluster. European Communities (2011)

11. Esteves, J., Pastor, J.A.: Organizational and technological critical success factors behavior along the ERP implementation phases. In: Enterprise Information Systems VI, pp. 63-71 (2006)

12. Donovan, R.M.: Why the controversy over ROI from ERP. Mid-range ERP (2000), http: / / www. midrangeERP.com

13. Griffith, T., Zammuto, R.F., Aiman-Smith, L.: Why New Technologies Fail. Industrial Management 41(3), 29-34 (1999); ABI/INFORM Global

14. Hong, K.-K., Kim, Y.-G.: The critical success factors for ERP implementation: an organizational fit perspective. Information \& Management 40, 25-40 (2002)

15. Hyötyläinen, R.: Implementation of technical change as organizational problem-solving process. Management of user activities (VTT Publications 337). Espoo: Technical Research Centre of Finland. Academic dissertation (1998) 
16. ITIL. An Introductory Overview of ITIL ${ }^{\circledR}$ V3. Best Management Practice. itSMF; The IT Service Management Forum (2007),

http://www.itsmfi.org/files/itSMF_ITILV3_Intro_Overview_0.pdf

17. Jeffery, B., Morrison, J.: ERP. One Letter at a Time. September 1, 2000 Issue of CIO Magazine (2000), http: / / www. cio.com

18. Karvonen, I.: SMEs and the implementation of information systems: how to succeed. In: Stanford-Smith, B., Chiozza, E. (eds.) E-work and E-commerce. Novel Solutions and Practices for a Global Networked Economy, vol. 2, pp. 1138-1144. IOS Press, Amsterdam (2001)

19. Koskinen, M.: On the Role of Interpretation Schemes in Organizational IS Implementation. In: Proceedings of the 39th Hawaii International Conference on System Sciences (2006)

20. Kurumluoglu, M., Nostdal, R., Karvonen, I.: Base concepts. In: Camarinha-Matos, L., Afsarmanesh, H., Ollus, M. (eds.) Systems and Practices Virtual Organizations, pp. 11-28. Springer, Heidelberg (2005)

21. Lanning, H.: Planning And Implementing Chang In Organisations - A Construct For Managing Change Projects. Dissertation at Helsinki University of Technology (2001)

22. Li, M.-S.: Enterprise activity in the Future Internet Assembly. FInES cluster meeting, June 2 (2010), http: / / cordis.europa.eu/fp7/ict/enet/

fines-meeting-20100602_en.html2.7.2010

23. Lin, H.-F.: Empirically testing innovation characteristics and organizational learning capabilities in e-business implementation success. Internet Research 18(1), 60-78 (2008)

24. Moore, J.: Predators and Prey: A New Ecology of Competition. Harvard Business Review (May/June 1993)

25. Munkvold, B.E.: Challenges in IT implementation for supporting collaboration in distributed organizations. European Journal of Information Systems 8, 260-272 (1999)

26. Nicolaou, A.I., Bhattachary, S.: Organizational performance effects of ERP systems usage: The impact of post-implementation changes. International Journal of Accounting Information Systems 7, 18-35 (2006)

27. Remus, U.: Critical success factors for enterprise portals. A comparison with ERP implementations. Business Process Management Journal 13(4), 538-552 (2007)

28. Scheer, A.-W., Habermann, F.: Enterprise resource planning: making ERP a success. Communications of the ACM 43(4), 57-61 (2000)

29. silicon.com: The practicalities of unified communications and collaboration (2009), http: / / www.silicon.com/special-features/

unified-communications/2009/11/17/

unified-comms-what-it-needs-to-succeed-39653038/

30. Sun, Y.T., Yazdani, A., Overend, J.D.: Achievement assessment for enterprise resource planning (ERP) system implementations based on critical success factors (CSFs). International Journal of Production Economics 98, 189-203 (2005)

31. Tolle, M., Vesterager, J.: VEM: Virtual Enterprise Methodology. In: Karvonen, et al. (eds.) Global Engineering and Manufacturing in Enterprise Networks (GLOBEMEN), VTT Symposium, vol. 224, pp. 53-70 (2003)

32. TT: Electronic Business in Finnish industry. TT - The Confederation of Finnish Industry and Employers (2000),

http://www.tt.fi/english/publications/tehoa.pdf

33. Umble, E.J., Haft, R.R., Umble, M.M.: Enterprise resource planning: Implementation procedures and critical success factors. European Journal of Operational Research 146, 241-257 (2003)

34. Wheatley, M.: ERP Training stinks. June 1, 2000 Issue of CIO magazine (2000), http://www.cio.com 